\title{
A New Experiment Teaching Mode for Network Security \& Law Enforcement Major to Meet the Need of New Engineering Talent Training
}

\author{
Zhijun Liu* \\ Information Technology Department \\ Hubei University of Police \\ Wuhan 430034, China \\ seraphtear@163.com
}

\author{
Ning Wang \\ Hubei Provincial Collaborative Innovation Center \\ for Digital Forensics and Trusted Application \\ Wuhan 430035, China \\ assemblylp@163.com
}

\begin{abstract}
The "New Engineering" is the direction of the engineering education reform based on the national strategic development and the new requirements for the cultivation of innovative talents. Experiment teaching is an important part of cultivating outstanding engineering and scientific talents with innovative and entrepreneur capabilities, and cross border integration capabilities. This paper selects the experiment teaching of network security \& law enforcement major in police higher education as the study object, firstly analyzes the problems existing in the experiment teaching process, then proposes the design of the hierarchical practical skills training mode and the student-centered experiment teaching mode, and finally explores the application of the presented methods in experiment teaching and introduces the achieved results. The preliminary actualization of experiment teaching demonstrates that it can effectively consolidate the content of theoretical teaching, cultivate students' practical ability and improve students' innovative thinking.
\end{abstract}

Keywords-new engineering education; experiment teaching; police education; talent training; major construction

\section{INTRODUCTION}

To against the backdrops of the global "industry 4.0" technological revolution and China's joining the Washington Accord agreement, china has outlined an initiative "New Engineering Education" to reform its engineering education at university level. China's Ministry of Education successively issued three policy documents, namely "Fudan Consensus", "Tianda Action' and "Beijing Compass", which have been the guiding principle for the new engineering construction [1].

Developing the ability of engineering students is the key point of the new engineering construction. In order to train large numbers of innovative talents that meet the newest economic and industrial demands, many universities in China have established a number of new programs over the past year in line with one of the basic requirements of new engineering policy documents. In addition, a number of majors of the universities have adjusted their course groups to develop interdisciplinary courses and increase the interdisciplinary features of existing courses.
According to the "Measures for the establishment and management of the subject catalogue of academic degreeawarding and personnel training([2011]11)" issued by the academic degrees committee of the State Council and the Ministry of Education, public security technical discipline (0838) was classified as independent first-class discipline of engineering, which includes eight secondary disciplines, such as criminal science and technology major, the fire engineering major, safety engineering major, network security \& law enforcement major, etc.[2].

In 2012, the network security \& law enforcement major was set up according to "the Undergraduate Specialty Catalogue of Higher Institutions (2012)" by the Ministry of Education, which was added in public security technical discipline [3]. The network security \& law enforcement major cultivates applied talents of maintaining the safety and order of network space security with high comprehensive quality, strong professional skills [4].

Experiment teaching is a key part of engineering teaching. With experiment teaching as an object of research, this paper explores the experiment teaching reform and student talent training of network security \& law enforcement major in our college. The rest of this paper is organized as follows, in Section II; the authors introduce the research backgrounds and motivations. The design of experiment teaching mode reform of network security \& law enforcement major is proposed in Section III. The experiment teaching implementations and conclusion are covered in Sections IV and V respectively.

\section{BACKGROUND AND MOTIVATION}

Approval of the Ministry of Education, from 2014 to today, the majority of the provincial police colleges and several political and law high schools were allowed to set up network security \& law enforcement major and started to enroll students Many police colleges and law high schools carried on beneficial explorations on the subject and major construction, teaching team construction, course construction, etc.[5-6]. This paper investigated the experiment teaching modes of several provincial police colleges which take the leading position in the field of the network security \& law enforcement major teaching and scientific research. According to the demands for 


\section{DESIGN OF THE EXPERIMENT TEACHING MODE}

cultivating talents with innovative application ability of the new engineering education, there exist some problems.

\section{A. Difficult to Adapt to the Practice Requirements of the Academic Frontier and Interdiscipline Subject}

The contents of the experiment teaching put too much emphasis on the validating experiments of the courses and pay less attention to the designing and comprehensive experiments. For example, the network attack and defense, applied cryptography, electronic data forensics technology, as the main major courses in network security \& law enforcement major, were mainly in classic experiments and had fewer extensive experiments. Furthermore, it also lacked the comprehensive experiments and creative experiments derived from several major courses integration. In addition, as a newly arisen and interdisciplinary major, the network security \& law enforcement major involved with computer science, the science of public security, management, sociological law, etc., the interdisciplinary nature is the main characteristic of this major. But the experiment projects reflected interdisciplinary characteristics are not many, which is difficult to adapt to the practice requirements of the academic frontier and interdisciplinary subject.

\section{B. Hard to Accomplish the Core Task of Talent Cultivation Against the Background of New Engineering}

According to our survey, at present, the experiment teaching method is teacher-centered in most provincial police colleges. The experiment process and experiment material have been set in advance and the students' experiment operations are in a purely mechanical manner, which will be a lack of gaining for independent thinking and self- innovation. For students, the fairly constant experiment content and experiment teaching method lead to a low level of motivation and interest in experiment courses. In addition, for some reason, few of the teachers have positive attitude towards the experiment teaching, development and practice of comprehensive and creative experiments done by the experiment teachers are not many, which will be hard to accomplish the core task of talent training against the background of the new engineering.

\section{Hard to Achieve the Goal of Talents Training under the New Engineering Education}

The new engineering education has proposed that the students' innovative thinking, students' innovative techniques and students' enterprise ability should be strengthened. Because of closer university-industry facilitating the quality of engineering education, university science parks, universityindustry cooperative laboratories, university-affiliated state key laboratories, and internship bases have sprung up in recent years[7-8]. To our best knowledge, the network security \& law enforcement major in most provincial police colleges have not yet applied systematic educational ideas of the innovation ideas and the innovation entrepreneurship to the talent training, the systematic experiment courses of innovative thinking and mature practical training platform are still inadequate.
Against the deficiency of the experiment teaching in existence, according to the principle of talent training under the new engineering education, we combine police college characteristics and major features, put forward and practice a new experiment teaching mode for network security \& law enforcement major.

\section{A. Hierarchical Practical Skills Training Mode}

The experiment of teaching should consolidate the content of theoretical teaching and cultivate students' practicability of professional skills training by pertinently designing and arranging the experiment content close to the practice of public security work. In addition, it should emphasize the development of students' innovative thinking, the ability of problem resolving, collaboration \&communicative ability, etc,. The 4-4-3 experiment teaching mode is proposed as shown in Fig.1.

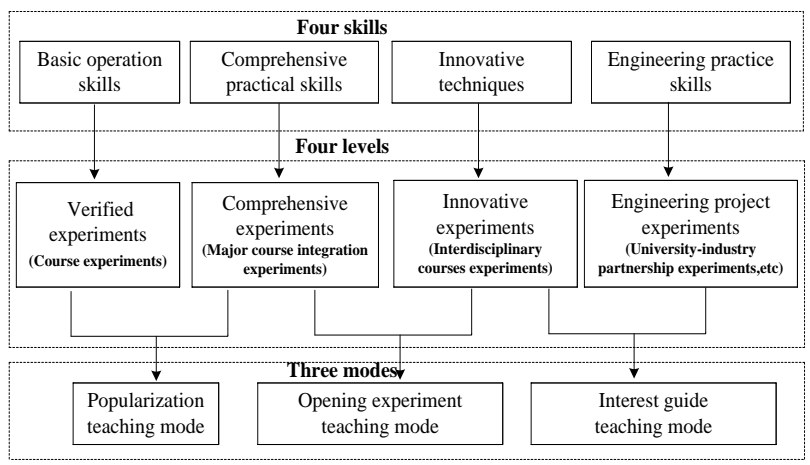

Fig. 1. The experiment teaching mode

For basic operation skills, the course experiments, mainly composed of verified experiments, were adopted for consolidating the content of theoretical teaching, cultivating students 'practical ability, all students in the course must attend the course experiments to grasp the experimental skills of the course. For example, in a database course, after studying the theoretical knowledge, the students must finish the course experiments, which include query operations of MIS, database concurrency skill operations, database backup skill operations, database recovery skill operations, etc.

The second-level experiment is comprehensive and designing experiment. The purpose is to widen students' knowledge, train their ability to gain knowledge actively and solve problems, and get a deeper understanding of the theory. The experiment contents come from the different major courses' integration, intercrossing and expansion. For example, database forensic experiments derive from the integration of database course, network criminal investigation course and digital forensics course. The experiment operations involve the criminal cases analysis, data extraction operations, standard operations of computer forensics, etc.

The innovative experiments aim at raising student's innovation ability. In recent years, the laboratory established in Henry Chang-Yu Lee's name and the University Innovation and Student Start-up Base of the Hubei University of Police 
the students participate in classroom discussion, debate, and questions in the experiment classroom teaching.

The second is to provide many experiment teaching resources outside of class and uses an exchange platform to create conditions for students to better grasp experiment contents, which include Micro class video of the experiment course, MOOCs + open laboratory, experiment teaching resource in the network, etc. The students should preview the contents beforehand, enter into the experiment classroom with problems, and study independently outside the classroom. In addition, the teacher adopts a combination model of online and offline, in-class experiments and after-class experiments for alleviating experiment teaching predicament with the limited hours and improving the experiment teaching results.

Thirdly, complied with the course teaching reform, the diversified experiment examination methods are provided. Most course experiment examinations are in the way of using computers in the computer lab or having in-class quizzes. For the comprehensive and innovative experiments, the teacher arranges the students in groups and organizes experiment items, students in groups select a project as their task and give explanation on what the project needs to do and how it needs to do, after designing and development of students' projects in a short period, a rejoin committee is formed by several teachers and the average score is given for every group. The process assessment method is also introduced to strengthen the review of students’ practice experience and manipulative ability [9].

\section{EXPERIMENT TEACHING IMPLEMENTATION AND EFFECTS}

\section{A. Experiment Teaching Implementation}

The problem-solving ability must be considered as the fundamental orientation for the talent training under the new engineering education, these problems include solving interdisciplinary and cross-border, comprehensive and complicated, future and frontier problems. The training of innovative spirit, innovation thought, the students' employability and entrepreneurial abilities should run through the whole education process. Based on this idea, a preliminary exploration of the experiment teaching implementation, also known as layered experiment teaching and systematic guidance, was carried out.

For the freshmen, to inspire students' innovative thinking, we set up the major-related general education courses, invited the police in the front line from practical police departments to give lectures, sponsored $\mathrm{C}$ language programming contest, etc. which would inspire the freshmen for a deeper understanding of the affinity between the basic knowledge and practical engineering projects.

For the juniors and sophomores, the basic major courses and major courses were set up, hierarchical practical skills training modes were adopted to consolidate the content of theoretical teaching, cultivate students 'practical ability and develop students' innovative thinking. In addition, some students' research projects were commissioned for the students in recent years, such as Henry Chang-Yu Lee's work laboratory, department of scientific management, etc. In the 
creative ability of students are very high, and especially the students have a strong practical ability on cybercrime investigation and digital evidence forensics.

\section{CONCLUSION}

Currently the talents' knowledge structure and innovation capacity training divorce from industry demand, and the problems are common to all universities in China. As a newly arisen and interdisciplinary major, there inevitably exist some problems that need to be solved in the network security \& law enforcement major development. This paper explores an experiment teaching mode for network security \& law enforcement major under the new engineering education, after several years of experiment teaching implementation, it still has a bit of room for improvement, especially in the area of effectively enhancing interdisciplinary features of courses, upgrading the course system to increase practical experiences. Overall, however, the new experiment teaching mode for network security \& law enforcement major will have a farreaching effect on police education, an indispensable part of higher education.

\section{ACKNOWLEDGMENT}

This work is supported by the teaching reform project of Hubei University of Police (JYXM2019B11, JYXM2019B06, and JYXM2018A04), the project of humanities and social sciences, the Ministry of Education in China (17YJCZH172). Finally, the authors would like to thank the anonymous reviewers for their time and valuable suggestions that contributed to the overall quality of this paper.

\section{REFERENCES}

[1] Tengteng Zhuang, Xiaoshu Xu, 'New Engineering Education' In Chinese Higher Education: Prospects and challenges, TUNING JOURNAL FOR HIGHER EDUCATION, Vol.6, No.1, pp.69-109, NOV 2018

[2] Liu Guangming, Zhou Zhangqi, Li Yanqing, Research on the construction of public security science discipline and public security technology discipline, Journal of Hubei University of Police, 2012, No.3 pp. 179-181(In Chinese)

[3] Luo Zhao, Chen Ya, Chen Yong, Research on Cultivation of Practical Combat-oriented Network Security and Law Enforcement Professionals, Journal of Guangxi Police College, 2017, No.1, pp. 116-120 (In Chinese)

[4] Zhou Jianhua, Chen Yanyu, Li Huanhuan, Research on Cultivation Goals and Approach of Network Security and Law Enforcement, Journal of Hubei Adult Education Institute, 2018, No.1, pp. 20-23(In Chinese)

[5] Liu Changwen, Tong Hui, Liu Ming, A Research on the Curriculum Construction of Network Security and Law Enforcement, Journal of Beijing Police College, 2014, No.4, pp. 113-116 (In Chinese)

[6] Liu Zhijun, Huang Fenglin, Exploration and Thinking on the Talent Training of Network Security and Law Enforcement, Journal of Hubei University of Police, 2017, 3, pp. 116-112 (In Chinese)

[7] Zhong Denghua. Connotation and actions for establishing the newly emerging education. Research in Higher Education of Engineering, 2017 No.3, pp. 7-12(In Chinese)

[8] Ye Min, Kong Hanbing, Zhang Wei. Emerging engineering education from idea to action. Research in Higher Education of Engineering, 2018, No.1, pp. 24-31 (In Chinese)

[9] Wang Ning, Liu Zhijun, Applying the Process Assessment Method into Computer Forensics Course in Police Higher Education, 2015 2nd International Conference on Education and Social Development (ICESD 2015), 2015, pp.496-510. been affirmed and highly praised by them, which generally
reflect the fast acceptability, comprehensive quality and 